\title{
Discoid lupus erythematosus with genital manifestations
}

\section{Samia Mrabat', Sara Elloudi ${ }^{1}$, Jihad Kassel', Zakia Douhi', Hanane Baybay ${ }^{1}$, Fatima Zahra Mernissi ${ }^{1}$, Soufiane Ennaciri ${ }^{2}$, Moulay Hassan Farih ${ }^{2}$}

${ }^{1}$ Department of Dermatology, University Hospital Hassan II, Fes, Morocco, ${ }^{2}$ Department of Urology, University Hospital Hassan II, Fes, Morocco

Corresponding author: Samia Mrabat, MD, E-mail: samiamrabat91@gmail.com

Sir,

A 56-year-old male with a long history of cutaneous lupus erythematosus affecting the ear and elbow had abandoned treatment for the last five years and presented with new lesions. A clinical examination revealed typical lesions of lupus discoid in the ear and right elbow (Fig. 1), as well as a well-demarcated, atrophic, erythematous, keratotic plaque with scales, $6 \times 8 \mathrm{~cm}$ in size, affecting the scrotum (Fig. 2). Dermoscopy revealed follicular keratotic plugs, white scales, and structureless whitish areas (Fig. 3).

In all types of lupus erythematosus, skin lesions appear typically in sun-exposed areas [1], but rarely on the genitalia, with a few cases reported in the literature.
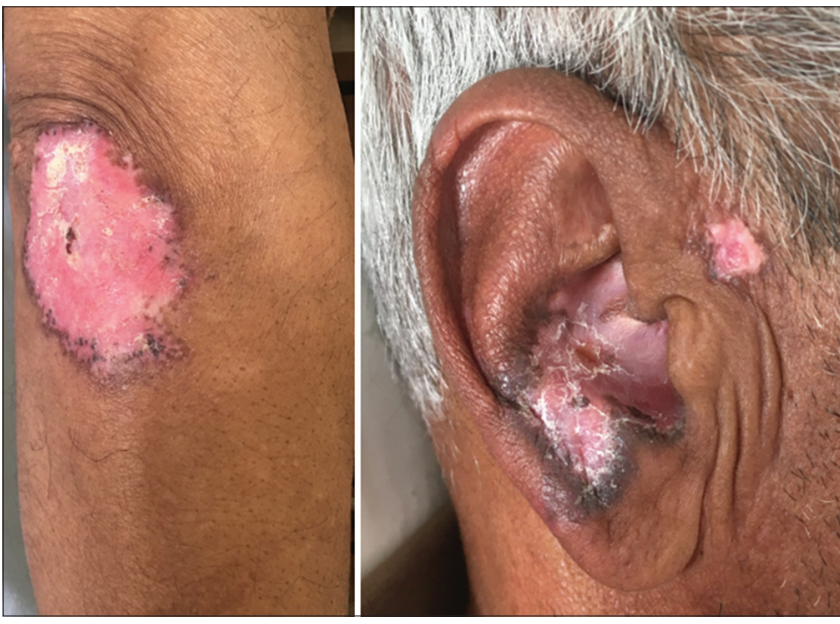

Figure 1: Erythematous plaques on the ear and elbow.

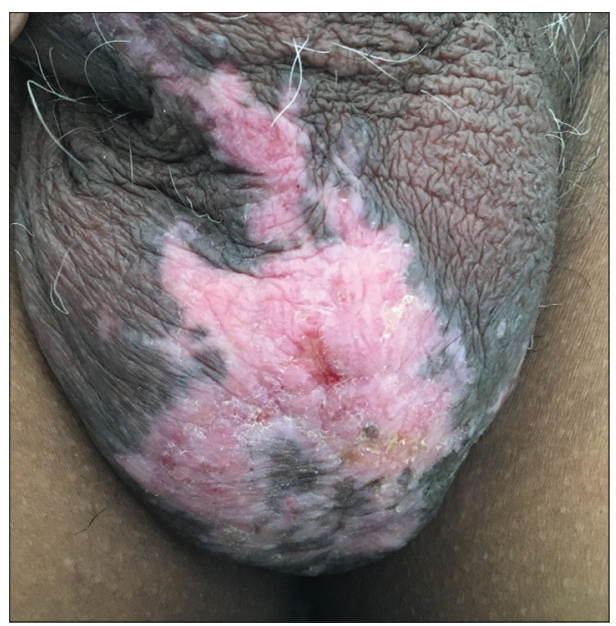

Figure 2: A well-demarcated, atrophic, erythematous, keratotic plaque with scales on the scrotal skin.

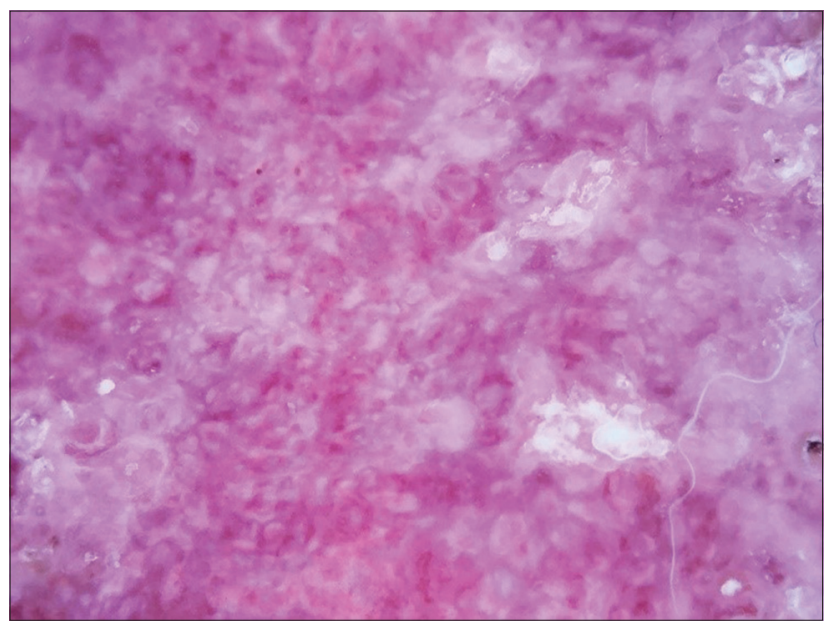

Figure 3: Follicular keratotic plugs, white scales, and structureless whitish areas.

\footnotetext{
How to cite this article: Mrabat S, Elloudi S, Kassel J, Douhi Z, Baybay H, Mernissi FZ, Ennaciri S, Hassan Farih M. Discoid lupus erythematosus with genital manifestations. Our Dermatol Online. 2021;12(2):218-219.

Submission: 21.10.2020; Acceptance: 26.12.2020

DOI: $10.7241 /$ ourd.20212.36
} 
The lesions that have been described are usually erosions or ulcers and erosive plaques on the mucous membranes and may be confused with other diseases [2]. A physician's increased awareness of this unusual manifestation of discoid cutaneous lupus is important. Untreated patients may be prone especially to scarring and disfigurement, and such sequelae are preventable by early diagnosis and treatment [3].

\section{Consent}

The examination of the patient was conducted according to the principles of the Declaration of Helsinki.

The authors certify that they have obtained all appropriate patient consent forms, in which the patients gave their consent for images and other clinical information to be included in the journal. The patients understand that their names and initials will not be published and due effort will be made to conceal their identity, but that anonymity cannot be guaranteed.

\section{REFERENCES}

1. Romiti R, Anzai A, Nico MM. Genital discoid lupus: A rare manifestation of cutaneous lupus erythematosus. Lupus. 2014;23:707-10.

2. Prenner J, Kelley K, Elkeeb D, Onajin O. Hypertrophic discoid lupus erythematosus of the vulva mimicking lichen simplex chronicus: A case report and review of the literature. Am J Dermatopathol. 2020;42:191-5.

3. Del Alcázar-Viladomiu E, López-Pestaña A, Tuneu-Valls A. Lupus erythematosus affecting the genitalia: An unusual site. Actas Dermosifiliogr. 2018;109:78-80.

Copyright by Samia Mrabat, et al. This is an open access article distributed under the terms of the Creative Commons Attribution License, which permits unrestricted use, distribution, and reproduction in any medium, provided the original author and source are credited.

Source of Support: Nil, Conflict of Interest: None declared. 